\title{
CIF - ABCPF Task Force Report on Cooperation and Unity November 1991
}

Editor's Note: The Task Force report was considered by the ABCPF council at its January 16, 1992 meeting and the following motion was passed:

"Whereas the joint ABCPF/CIF Task Force has proposed a structural change to both organizations, and whereas the Council of the ABCPF agrees with the need for change but believes that options other than the single proposal put forward by the Task Force exist, it is moved that Council adopt the position that the ABCPF will seek a formal partnership with the CIF which: (a) is consistent with the approved mission of the $\mathrm{ABCPF}$, and (b) recognizes and corrects the shortfalls identified by the task force."

The Council felt that this position opened the door for negotiation and discussion without limiting the council to the Task Force recommendation.

The CIF/IFC supports the Task Force recommendations and, with the full participation and agreement of the B.C. Sections, will discuss any options the $\mathrm{ABCPF}$ wishes to explore.

The CIF/IFC has also distributed this report to all other RPF associations and further areas of cooperation are being looked at in other provinces.

\section{Executive Summary}

The Task Force on Cooperation and Unity has concluded that urgent changes are needed to meet the forestry community's political and professional challenges over the next decade. The current structures, duties, roles and organization of the Canadian Institute of Forestry (CIF) and Association of B.C. Professional Foresters (ABCPF) are impediments to addressing the important forestry and professional issues, especially at the regional and provincial levels. Valuable limited resources are being wasted on duplication of roles by a comparatively small membership base. Minor tinkering with current relationships will not solve the inherent problems. Major changes are recommended as a result of reviews of organizational structures representing other professions.

The Task Force recommends two new forestry bodies be established to replace the $C I F$ and $A B C P F$. The
British Columbia College of Professional Foresters would be responsible for the registration, discipline and competence maintenance of the forestry profession in B.C. The Forestry Institute of British Columbia (FIBC) would be responsible for promotion of forestry views and the political and public education programs of the forestry community at the regional and provincial levels. As well, the FIBC would be the B.C. wing of the national Canadian Institute of Forestry. The proposal includes mandatory membership in both organizations for all professionals. Technicians, technologists and other specialists are welcome as full members of FIBC. The clarity of roles offered by these proposals will lead to renewed activity and sharpened focus by the forestry community.

\section{Introduction}

The strength of an organization is dependent on leadership, member participation, and both public and membership perception of effectiveness. The forestry community's challenges of the coming decade necessitate a critical review of existing structures and networks relative to the needs of the public, the profession and other forestry interests. In British Columbia the environmentalist interests have been extremely effective in displacing the professional forester as the spokesperson for good environmental and forest management. The public perception and agenda on forests and their management is being established by others. The voice of the profession has been constrained by structural and perceived jurisdictional differences in the Canadian Institute of Forestry (CIF) and the Association of British Columbia Professional Foresters (ABCPF). The efforts of the few active members of these relatively small groups are, at times, wasted through maintenance of existing structures. The elected leadership and many members of the CIF and the $\mathrm{ABCPF}$ have long acknowledged and bemoaned the generally poor effectiveness of the two organizations in several key areas.

While the CIF has been able to maintain some prominence and political contacts at the national level it is virtually unknown in Victoria. The fact that less than $25 \%$ of B.C. foresters are CIF members reflects on local foresters' belief that the CIF has little relevance to his or her regional or provincial interests. The current malaise in active participation by members of the CIF is alarming. Most CIF Section activity in B.C. is dismal with many activities insular and self-serving. Few section executives maintain consistent local political or media relationships. Many B.C. Sections have come and gone in the past few years. There has been little sustained co-ordination at the provincial level. The CIF is rarely consulted or seen as effective by the political or media interests in B.C. and is almost unknown to the public or special interest groups concerned with the environment.

Historically, the ABCPF has had some major successes in the public/ political arena. Regional and provincial level action by past Councils and their Regional Public Affairs Committees (RPACs) were largely responsible for basic reforestation legislation and the securing of a significant Forest Resource Development Agreement. However, the $\mathrm{ABCPF}$ has been virtually absent in the environmental debates of the past few years. The profession has struggled to get its act together in the Discipline and Ethics areas. Minimal effort has been expended on the continuing education needs of its members. Only a few RPACs out of the original 15 or so still exist. Reorganization, restaffing, and seemingly endless inner contemplation has left the ABCPF in some disarray and poorly focused. The attempt to address all aspects of the ABCPF's very wide mandate has led to a dilution of its effectiveness.

The leadership of the CIF and $\mathrm{ABCPF}$ are working harder than ever but achieve less because of lack of member support, loss of volunteer assistance on projects and the general perception by many members that both organizations are not very effective at addressing their basic mandates. The lack of clearly defined roles and relationships hampers significant achievements. The forestry community and 
society will pay dearly for this lack of activity unless significant changes are made.

\section{Task Force on Cooperation and Unity}

In December 1990, the executives of the $\mathrm{CIF}$ and the ABCPF appointed two representatives from each organization as a Task Force to address several issues. The goals of the study were developed by this committee and approved by the executive of each organization.

The Task Force on Cooperation and Unity was asked to provide recommendations to:

- Improve effectiveness in both the quality and delivery of the forestry message to the public and governments.

- Strengthen the two organizations through cooperation and coordination.

In addition the committee was to offer a Vision of the two organizations in the short (immediate to 3 years) and the long term (10 years).

\section{Activities and Analysis}

After lengthy analysis of the current organizational structures, legal commitments and comparisons with other disciplines several conclusions regarding the Task Force goals were evident. It was apparent that our initial plan to focus on narrow interpretations of current responsibilities and seeking potential cooperation between the CIF and $\mathrm{ABCPF}$ was not going to address the fundamental structural problems for the relatively small (less than 3000 ) membership. We realized that there are some basic organizational changes that must be addressed in the short and long term. The CIF and ABCPF need to enhance the effectiveness of the forestry message, fulfill professional responsibility and serve the public interest.

We looked at the organizational structures and responsibilities of several other professions with similar legal and public information mandates to forestry:

- Provincial licensing including right to title and practice legislation

- Disciplinary authority over members at the provincial level

- National body for national issues

- Provincial body for provincial issues

- Regional organization for member activity at local level

The most appropriate model from our analysis was the Legal Profession. The lawyers have an organizational structure that promotes the type of activities and responsibilities we believe are best suited to forestry needs. There is a clear distinction between:

- licencing, discipline and competence maintenance

- political, public information, and government advisory roles

- regional, provincial and national structures

We examined other professions including the doctors and teachers. Both of these professions also have very similar structures to the Legal Profession. We are unaware of any other group which has structures similar to the combination licensing/political mandate of the ABCPF and the limited provincial presence of a national organization such as the CIF.

The following table is a detailed analysis of relationships and responsibilities in the legal and forestry areas at the national, provincial and regional levels. We have included this comparison as an aid to understanding the complexity of the relationships and purposes of the various bodies in each profession.

The organizational structures from the national to provincial to regional levels are similar for the Legal and Forestry professions. However, the Legal profession's organization appears much more effective in public education. This can be attributed to the clarity of responsibilities with which the national (Canadian Bar Association (CBA)) and provincial (Law Society (LS)) bodies have been endowed. The CBA holds sole responsibility for representing lawyers in current issues involving the public and the law. The LS limits itself to being a registering body and one that upholds the standards of the profession.

In the Forestry profession, the $\mathrm{ABCPF}$ has sole responsibility for the registration and discipline of foresters, but also has a mandate in the political/ technical arena at the provincial and federal levels. The CIF, while claiming the role of leadership in professional education also assumes major responsibilities for disseminating public information and political action at national, provincial and regional levels. In this era of environmental activism both the $\mathrm{ABCPF}$ and CIF have attempted proactive stances with little effectiveness. This has resulted in overlapping of roles, duplication of effort and minimal results. Since most active foresters belong to both bodies, confusion reigns and the question of "which organization is responsible for what?" has been asked by many.

Should all B.C. Professional Foresters be required to join the CIF? For those R.P.F.s who are currently not members of the CIF, the resulting increase in total fees (estimated at less than $40 \%$ ) to belong to both bodies might be considered by some to be onerous in view of questionable benefits. However, the resulting increase in membership to over 4000 would likely strengthen the CIF's ability to respond in the public/political arena both nationally and provincially. Joint membership is already in place in Alberta and seems to be working well. As well the addition of $1600+$ new members would probably lower the costs to service all members. A recent analysis supplied to the task force indicated a marginal cost of about $\$ 50$ per person to add 1600 new members to the CIF.

Would membership by all foresters in both organizations eliminate the confusion of who does what regarding education? Since such dual membership would not redefine the roles of the two bodies, the answer is "No". Even though 2000 foresters seem a large number of members for an organization, this is small in comparison with other disciplines such as B.C. teachers $(28,000)$ or engineers $(14,000)$. The task force believes that the profession cannot afford to waste relatively small numbers of active foresters by maintaining two organizations with overlapping mandates. A sharper focus is required.

From the politician's and the public's point of view, it would be a relief to clearly understand who was responsible for what in the B.C. forestry scene. In the areas of professional and public interface a clear line of communication and organization from the regional to the provincial to the national levels makes sense.

\section{Time for Change}

The Task Force on Cooperation and Unity has developed a vision which we believe will satisfy the objectives of making the Professional Forestry community more effective in dealing with forestry issues, maintaining the profession's integrity and protecting the 
A comparison of the organization of the legal and forestry professions as they occur in British Columbia

\section{FORESTRY}

\section{Canadian Institute of Forestry}

Purpose

- to serve as a leader and spokesperson for Canadian Foresters in both National and International arenas:

- to serve as a unifying body for Canadian Foresters;

- to disseminate forestry information on a national basis through newsletters and particularly through publication of The Forestry Chronicle;

- to foster the exchange of information through annual general meetings;

- to recognize education achievements at the University level by presenting medals and graduation rings:

- to recognize outstanding Forestry contributions at the national level through the presentation of awards:

- to promote the holding of a National Forestry Week.

\section{LEGAL}

\section{Canadian Bar Association}

Purpose

- to advance the science of jurisprudence across the country;

- to promote the administration of legislation throughout Canada:

- to foster harmonious relations and cooperation among incorporated Law Societies and cordial intercourse among members;

- to encourage high standards of legal education, training and ethics:

- to promote the occurrence of a National Law Week:

- to publish a national (bilingual) newsletter, Bar Talk

\section{Provincial Bodies \\ Representation}

The C.I.F. is represented in each province (or in some cases, part of a province) by SECTIONS:

Purpose

- to organize programs of a technical, professional and social nature;

- to actively participate in forest policy discussions at the provincial and national levels:

- to publish newsletters:

- to participate in activities
The C.B.A. is represented in each province by a Provincial BRANCH:

Purpose

- to review new legislation;

- to initiate law reform measures:

- to ensure the continuing education of the legal profession;

- to promote and improve the image of lawyers in the eyes of the public;

- to publish newsletters (Bar Talk).

In B.C., membership in the Canadian Institute of Forestry is voluntary! This is not true for all provinces (e.g., Alberta).

\section{Membership}

In B.C., membership in the Canadian Bar Association is automatic, since membership dues are collected by the Provincial Law Society. This is not the case for all provinces.

\section{Provincial Bodies}

\section{Membership}

\section{Association of British Columbia Professional Foresters}

Obligatory for practicing foresters.

Authority: Foresters Act 1979.

\section{Purpose}

- to maintain a register of those qualified to use the professional title and seal, and to practice forestry in B.C.:

- to maintain professional standards of members and to enquire into questionable conduct when required to do so, and to administer disciplinary procedures when such are found necessary:

- to ensure that the forests of B.C. are managed by professional foresters:

- to promote policies of integrated use of forest resources on public land:

- to advise the public and governments of the implications of policies affecting the use and management of forest land.

\section{Law Society of British Columbia}

Obligatory for practicing lawyers.

Authority: Legal Profession Act.

Purpose

- to maintain a register of those qualified to practice as lawyers in B.C.;

- to uphold and protect the public interest in the administration of justice by:

(a) preserving and protecting the freedoms of all persons;

(b) ensuring the independence and integrity of its members;

(c) establishing standards for education, professional responsibility and competance of its members and applicants for membership;

- to regulate the practice of law and uphold and protect the interest of its members;

- to publish a bi-monthly newsletter, The Advocate.

\section{Local Representation}

The ABCPF is represented locally by semi-formal Regional Public Affair Committees (R.P.A.C.).

Purpose

- to advise the public and governments of forestry issues;

- to strengthen communication between Council and members:

- to provide regional representation, and:

- to increase local involvement in forestry issues.
The Law Society is represented locally by Benchers, there being 26 of these positions across the province elected locally from geoqualified units called Counties. Counties with large populations have more benchers than those with small.

Purpose

- to represent local members' issues to the L.S.;

- to report to members on issues under discussion at the L.S. level.

Continuing Legal Education Society of British Columbia

Authority: Societies Act.

Purpose

- to administer Post Legal Training Courses during articling leading to examinations for full memberships in the legal profession.

This society is funded by the Law Foundation and fees for the P.L.T.S. 
public's interest. The new structures are aimed at addressing the fundamental confusion of roles and creating a revised spirit of activism in the profession, especially at the regional level. We do not intend the reduction of importance or influence of either the CIF or $\mathrm{ABCPF}$. We do recommend strengthening through reorganization, renaming and renewed focus. It is our sincere desire to see the activism and dedication currently at the executive levels of both the CIF and ABCPF mirrored at the provincial and regional levels where members can truly influence public policy and direction.

Under the Task Force proposal forestry issues and professional standards in B.C. would be addressed by two new organizations:

\section{The British Columbia College of Professional Foresters \\ The Forestry Institute of British Columbia}

We believe the changes required are so significant that a re-naming of organizations is needed to create a sense of excitement amongst our members and the public. These changes will show the forestry community's commitment to better addressing the challenges of the new decade and public concerns for the welfare of their forests.

\section{The B.C. College of \\ Professional Foresters}

The B.C. College of Professional Foresters will be responsible for registration and licensing of Professional Foresters, maintenance of Codes of Ethics to govern the behaviour of its members and their continuing education needs.

Legal Basis. Foresters Act of British Columbia with appropriate revisions as to name only. No other act revisions are required to implement these changes. The Bylaws also do not require any change.

Structure. The council structure currently in place at the $\mathrm{ABCPF}$ will continue, but with the following changes:

(a) those responsibilities pertaining to the production of position papers, the promotion of public awareness, forest policy issues etc. will cease to exist.

(b) the RPAC committees of the $\mathrm{ABCPF}$ will no longer be necessary.
A Regional structure will be maintained for addressing the Continuing Education needs for College members only. The new Forestry Continuing Studies Network will also be used for this purpose.

(c) A non-RPF be appointed to the Council or Board to represent the public.

(d) Council would be elected by a ballot of all members of the college.

Terms of Reference

(a) to ensure that the forests of B.C. are managed by professional foresters.

(b) to examine and admit to membership rolls those individuals who meet requirements set by the College.

(c) to maintain a register of those eligible to use the seal and title, and to practice professional forestry in B.C.

(d) to ensure that members keep up to date with latest requirements of the profession in B.C.

(e) to enquire into the questionable conduct of members when required to do so.

(f) to administer disciplinary procedures when such are found necessary.

(g) to uphold and review the Code of Ethics as required.

(h) to organize and maintain opportunities for continuing education to maintain professional competence.

Membership. As at present.

Financial. A single fee will be payable by all RPFs which will finance the operations of and membership in the College, the Forestry Institute of B.C., and the Canadian Institute of Forestry.

Interrelationships. The College would be expected to maintain close ties with its sister organization and share office and administrative resources with the new FIBC.

\section{The Forestry Institute of British Columbia}

The Forestry Institute of B.C. will be the provincial body of the Canadian Institute of Forestry in British Columbia and will be responsible for commenting on forest practices, involvement in political issues, and maintaining an active public stance. It will be responsible for all aspects of promoting the forestry message at the political level within British
Columbia. At the national level the CIF will continue to represent the views of British Columbia members of FIBC.

Terms of Reference. Same as current plus all public related functions of the former $\mathrm{ABCPF}$.

Membership. All B.C. RPF's plus anyone with a forestry qualification as presently allowed by CIF Sections in B.C.

Legal Basis. Provincial Societies Act

Financial. Dues from all College of Professional Foresters members. Dues from other members as at present. The funds given to FIBC from the College will finance the FIBC Provincial Council, CIF National Operations and the Regional Branches of FIBC.

\section{FIBC Provincial Council}

At the Provincial level the new Forestry Institute of British Columbia must quickly become the political voice of the professional and technical forestry community and be identified by the public and politicians as the voice of B.C. foresters.

Structure. Executive committee/ council will be comprised of the elected chairpersons or representatives from six or eight regional committees. From these members a FIBC President will be elected. The Presidency should be a fulltime, remunerated position and be well supported by staff and resources. Sharing of office space and staff with B.C. College of Foresters should be an objective.

Terms of Reference.

(a) to promote public awareness of B.C.'s forest policy.

(b) to advise the public and government of effects of existing and proposed legislation.

(c) to review new legislation affecting forest management practices in B.C.

(d) to promote policies of integrated use of forest resources.

(e) to speak for the forestry profession of B.C. on all matters relating to forest resources and their management.

(f) to be involved in the maintenance of a Code of Forest Practices.

(g) to represent B.C. forestry views at the national level of the CIF.

(h) to publish a provincial newsletter which will include local news, views, issues, policy perspectives, etc. 
(i) to be active in developing regional and local public advisory committees on forest management tied into provincial Roundtable Committees on Sustainable Economic Development.

The Council of the FIBC will be expected to have a permanent executive position on the National Board of the $\mathrm{CIF}$ in recognition of the largest provincial group in the CIF (over $45 \%$ of CIF members would be B.C. residents).

\section{FIBC Branches}

The regional level within British Columbia is expected to be the strength and foundation of the FIBC. The province will be subdivided into approximately six or eight areas, based on rational populations of foresters and members. These regional units of the FIBC will be known as Branches.

Structure. Similar to the current CIF Sections but with enhanced support and stability. Larger branches would maintain regional offices.

\section{Terms of Reference}

(a) to be the voice of B.C.'s forestry community at the local and regional level.

(b) to become involved with local issues relating to forest resources and their management.

(c) to promote integrated use of forest resources on a local level.

(d) to represent local issues at the provincial and national level through the FIBC Council and national CIF executive.

(e) to play a major role in the local observations of National Forestry Week. (f) to represent the professional and technical forestry voice to local government.

(g) to stimulate, encourage, promote and participate in the establishment and operation of local committees on sustainable development and integrated forest management.

Obviously the current executive of the ABCPF and CIF must develop further the concepts outlined in this report and refine the details. We have outlined the basic changes needed to address the current concerns and develop a renewed activism amongst the profession and the forestry community. We believe our approach is sensible and eliminates the confusion over roles and strengthens both the professional practice and public interface without compromising either. The recommended structure is a workable solution as evidenced by its adoption by other professions. The changes also build on the heritage and legacies of the profession and the CIF in British Columbia.

\section{Implementation}

The Task Force on Cooperation and Unity would be pleased to clarify any aspect of the report or topics discussed herein. It must be noted that a number of other issues were reviewed and discussed by the Task Force specific to the original terms of reference. The Task Force is prepared to review these if desired.

The need for restructuring the purpose and terms of reference for the CIF and $\mathrm{ABCPF}$ is immediate. If the will to implement these recommendations exists, both the College and Forestry
Institute could be completely functional within three years or less.

The Task Force recommends a joint committee comprised of a member of the CIF National Executive from B.C., two BC CIF Section Chairpersons and several ABCPF Council members address in more detail the recommendations in this report. We believe this task could be accomplished in a relatively short time frame and a ballot proposal could be submitted to all BC $\mathrm{CIF}$ and $\mathrm{ABCPF}$ members by the Fall of 1992.

Once the mandate for the changes in name, structure and terms of reference has been obtained, an implementation committee consisting of members from both organizations should be appointed. The terms of reference of this committee should include the orderly and expedient implementation of the recommendations included in this report.

W.E. Dumont, R.P.F. J.W. Toovey, R.P.F. D.A. Smith, R.P.F W.W. Bourgeois, R.P.F.

\section{A CIF/IFC \\ CORPORATE SUSTAINING MEMBER}

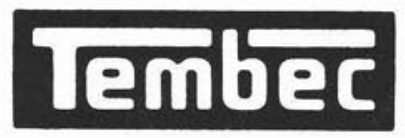

\section{The Forestry Comical}

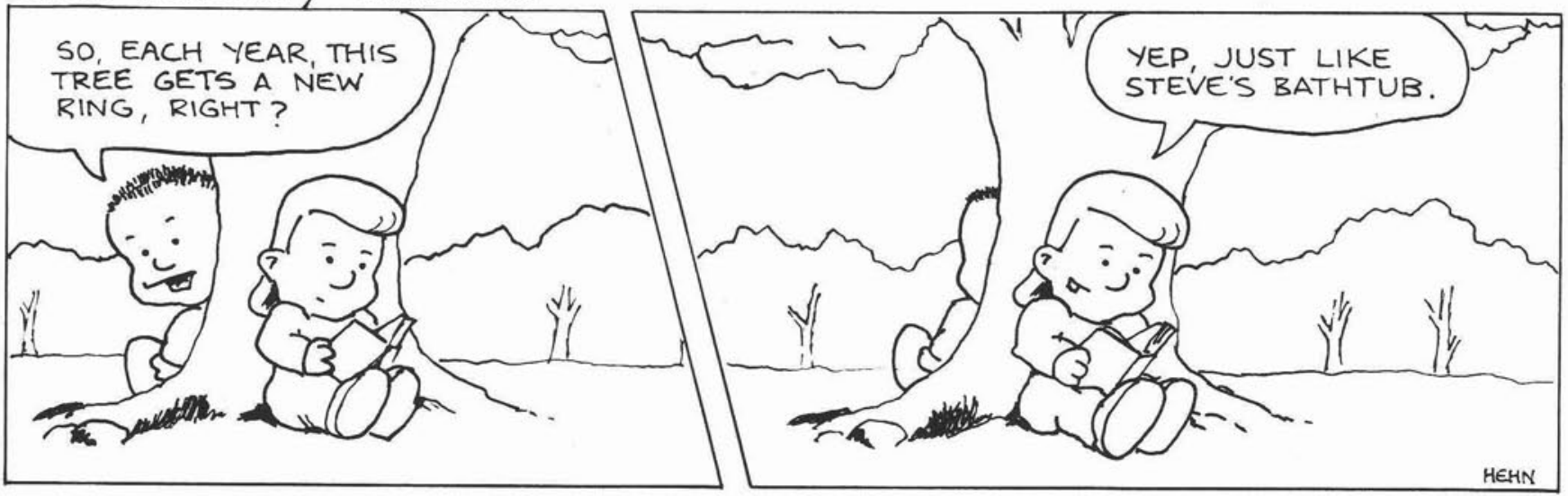




\section{MacFOLIA TM}

For automatic and interactive

leaf analysis

From:

RÉGENT INSTRUMENTS Inc.

P.O.Box 75 Lac-St-Charles, Qué. Canada GOA $2 \mathrm{HO}$

Tel \& FAX: 418-849-0244

Designed with:

SWISS FEDERAL INSTITUTE OF TECHNOLOGY ZURICH
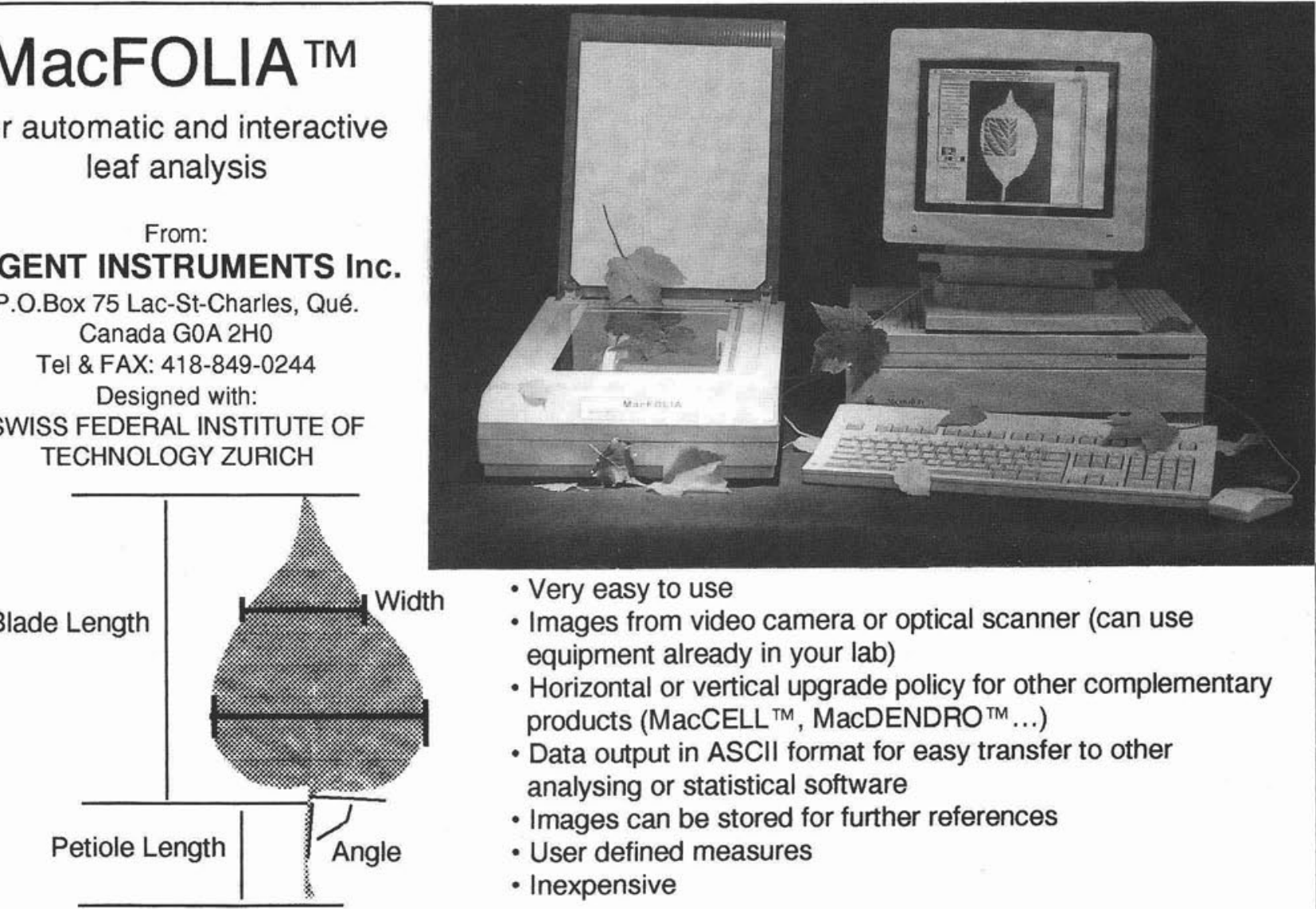

- Very easy to use

- Images from video camera or optical scanner (can use equipment already in your lab)

- Horizontal or vertical upgrade policy for other complementary products (MacCELL ${ }^{\mathrm{TM}}$, MacDENDRO ${ }^{\mathrm{Tm}}$...)

- Data output in ASCII format for easy transfer to other analysing or statistical software

- Images can be stored for further references

- User defined measures

- Inexpensive

\section{CIF/IFC Special and General Awards and Prizes}

This is the third and final article on the subject of Institute Awards and Prizes $^{1}$. These include special awards as well as a series of general awards to foresters who may or may not be members of the Institute and others who have made exceptional contributions to forestry in Canada.

\section{Honorary and Fellow Members}

The constitution adopted at the founding meeting in 1908 divided the membership into four classes: Honorary, Active, Associate and Student. Honorary members were defined as "individuals connected with forestry in any of its aspects who shall be elected by members of the Society.', The first Honorary Members was elected in 1913 and the C.S.F.E. and

'For., Chron. 68: 152-153 and For. Chron. 68: 266-268.
CIF/IFC continued to elect worthy individuals, whether foresters or not, to this class until 1973. The proportion of the total membership contained by these two classes is always small, usually between $1 \%$ and $2 \%$. In March, 1992, it was $1.6 \%$, as shown below.

The membership in March, 1992 is: No. $\%$

Active............. $1814 \quad 78.6$

Honorary . . . . . . . . . . $6 \quad 0.3$

Fellow ............. $32 \quad 1.3$

Retired ........... $315 \quad 13.7$

Student . . . . . . . . . . $142 \quad 6.1$

Total

100.0

The Annual Meeting of 1973 introduced the class "Fellow Member", to recognize members of the Institute and reserved the class "Honorary Member', for non-members who had made comparable contributions. In 1973, all Honorary Members who previously had been Active or Associate Members of the Institute were reclassified as Fellow Members.
Honorary Members elected from 1913 to 1972

1913 Thomas Southwood

1919 Ricardo Codorniu

1927 C.E. Lane Poole

1927 Major-General Lord Lovat

1927 C.E. Legat

1927 Sir Peter Clutterbuck

1927 Professor Tor Jonson

1927 Colonel W.B. Greeley

1936 Major-General A.G.L. McNaughton

1942 Dr. C.D. Howe

1942 Norman M. Ross

1943 Ellwood Wilson

1944 F.W.H. Jacombe

1949 Dr. J.M. Swaine

1950 E.J. Zavitz

1953 Dr. J.H. White

1956 Dr. H.R. MacMillan*

1956 Dr. R.B. Miller

1957 Professor T.W. Dwight*

1957 Dr. H.T. Gussow

1958 D. Roy Cameron*

1958 B.F. (Ben) Avery

1958 Dr. C.D. (Dick) Orchard

1959 Roy Campbell

1960 J.O. Wilson*

1961 W.W. (Bill) McCormack* 